\title{
Simulation on Toxic Gases in Vehicle Exhaust Equipped with Modified Catalytic Converter : A Review
}

\author{
A.M. Leman ${ }^{1, *}$, Fakhrurrazi Rahman ${ }^{1}$, Afiqah Jajuli ${ }^{1}$, Winardi Sani ${ }^{1}$, Supa'at Zakaria ${ }^{1}$ and \\ Dafit Feriyanto ${ }^{1}$ \\ ${ }^{1}$ Faculty of Engineering Technology, Universiti Tun Hussein Onn Malaysia (UTHM), \\ Parit Raja, Batu Pahat, 86400 Johor, Malaysia.
}

\begin{abstract}
Air pollution and global warming is a major issue nowadays. One of the main contributors to be the emission of harmful gases produced by vehicle exhausts lines. The harmful gases like NOx, CO, unburned HC and particulate matter increases the global warming, so catalytic converter plays a vital role in reducing harmful gases. Catalytic converters are used on most vehicles on the road today. This research deals with the gas emission flow in the catalytic converter involving the heat transfer, velocity flow, back pressure and others chemical reaction in the modified catalytic converter by using $\mathrm{FeCrAl}$ as a substrate that is treated using the ultrasonic bath and electroplating techniques. The objective of this study is to obtain a quantitative description of the gas emission in the catalytic converter system of automobile exhaust gas using ANSYS Software. The description of the gas emission in the catalytic converter system of automobile exhaust gas using ANSYS Software was simulated in this research in order to provide better efficiency and ease the reusability of the catalytic converter by comparing experimental data with software analysing data. The result will be expected to demonstrate a good approximation of gas emission in the modified catalytic converter simulation data compared to experimental data in order to verify the effectiveness of modified catalytic converter. Therefore studies on simulation of flow through the modified catalytic converter are very important to increase the accuracy of the obtained emission result.
\end{abstract}

\section{Introduction}

The development of new technology that aims in lowering environmental impact has become one of the most interesting and challenging issues in automotive engineering. Researchers must contribute new ideas to further decrease exhaust emission for automobiles. A serious issue that is always been debated among the environmentalists over the decades and recent years is air pollution. One of the main contributors is said to be the emission of harmful gases produced by vehicle exhaust lines [1]. Vehicles natural gas engine are facing a problem with the engine combustion as the in-cylinder produced high

\footnotetext{
* Corresponding author : mutalib@uthm.edu.my
} 
unburned hydrocarbon (HC) and also carbon monoxide (CO) gas emission through the vehicle's exhaust [2]. The emission of nitrogen oxide $\left(\mathrm{NO}_{\mathrm{x}}\right)$ is depending on cylinder fuel combustion; either the emission is increasing or decreasing [3]. However, the pollutant gaseous can be reduced either by the thermal or catalytic system.

Mansha $\mathrm{M}$ et al. stated that there are two methods that were usually being practiced to reduce the harmful adapted from the emission gases of automobiles exhaust which is by improving the automobile's engine technology and the composition of fuels. The new improvement of alternative fuels composition not only creating better combustions for vehicles exhaust but also might lower the emission [4]. The other method is after treatment process of exhaust gases which mostly vehicle used a catalytic converter. The catalytic converter is commonly installed as a device in the exhaust system of an automobile to convert toxic exhaust gas into less harmful gas. Catalyst metals are introduced in the catalytic converter to increase the rate of destruction of toxic gases such as carbon monoxide, nitrogen oxide and unburned fuel resulted from incomplete combustion of fuel [5]. It is a component that has become very effective in reducing the pollutants emission from the vehicles exhaust in the last 15 years. The chemical kinetics for the various heterogeneous reactions in a catalytic converter depend on several factors and have to be determined accurately for good qualitative and quantitative predictions by the model. The reaction rates are different for each wash coat formulation and cannot be determined a priori because (1) the kinetics are very sensitive to the wash coat formulation, (2) catalytic processes suffer from aging and deactivation, (3) the reaction path depends on the possible presence of species in real exhaust gas that are not present in controlled experimental studies, and (4) the kinetics is sensitive to feed composition and temperature [6]. The three pollutants of concern emitted from the spark ignition engines are unburned $\mathrm{HC}, \mathrm{CO}$ and NOx (currently regulated). Unburned $\mathrm{HC}$ and $\mathrm{CO}$ are generated due to inefficient combustion while the thermal NOx is formed when nitrogen reacts with excess oxygen at higher temperature $\left(>180^{\circ} \mathrm{K}\right)$ in the combustion process and is the predominant form produced by Zeldovich Mechanism in combustion engines [7].

The effectiveness of catalytic converters is depending on the temperature gas temperature which is usually less effective during cold start [8] [9]. Thus, in order to shorten the time for the catalytic converter reaches light-off temperature, detailed analysis using computational software must be done.

\section{Literature Review}

\subsection{Catalytic Converter}

A catalytic converter is a device used to reduce the pollutant gaseous from the internal combustion of vehicles engine. It is placed between the tailpipe of vehicle exhaust and engine manifold. The effect of the combustion in the engine will produce pollutant gaseous which is flowing out of the engine to be pass through the tailpipe and undergo a chemical reaction with the catalyst within the porous wash coat in the converter to produce a harmless gaseous before the harmless gaseous is exposed to the atmosphere. The catalytic converter is a stainless steel container mounted somewhere along the exhaust pipe of the engine and inside the container is a porous ceramic structure through which the exhaust gas flows [10]. In most converters, the ceramic is a single honeycomb structure with many flow passages. The passages comprise of many shapes, including square, triangular, hexagonal and sinusoidal [1].

Early converters used loose granular ceramic with the gas passing between the packed spheres. Since it is difficult to keep the spheres in place, many converter developers opted 
for ceramic monolith which offers various advantages. Among these advantages are smaller volumes, lower mass and greater ease of packaging [11]. Catalytic Converters are important post-combustion after treatment devices mounted in the exhaust system of engines to reduce engine out exhaust emissions and are classified as Two-Way or Three-Way. TwoWay Catalytic Converter works on two gases, $\mathrm{CO}$ and unburned $\mathrm{HC}$ while the NOx is controlled through exhaust gas recirculation (EGR) and by retarding the ignition timing [4].

\subsection{Catalyst Material}

Catalysts used in catalytic converters are from various types of materials. Mostly developed catalyst is Platinum Group Metal as the main role for this group is to oxidise carbon monoxide $(\mathrm{CO})$ and unburned hydrocarbon $(\mathrm{HC})$ exist from the engine combustion. [12] state that the effectiveness of platinum $(\mathrm{Pt})$ is under an oxygen-excessive condition which it is often being the metal of choice for the diesel application while for the vehicles that powered by petrol, platinum $(\mathrm{Pt})$ and palladium $(\mathrm{Pd})$ are suitable materials for catalyst development. Platinum (Pt) has several advantages to be highlighted which are; the high melting point, the interaction with poisons are limited to the metal surface such as sulphur compounds and platinum also can be efficiently recycled. However, there are recent studies that show the negative effects of the platinum (Pt) usage. Shahar and Majib (2007) [13] state that platinum $(\mathrm{Pt})$ content of road dust which is partially soluble as the dust may dissolve in water, ground and also the food chain. On the other hand, Platinum Group Metal also has some side effects which can lead to asthma, hair loss effect, dermatitis and other critical health problem in human [14]. The installation of the converter using Platinum Group Metal as a catalyst is quite expensive in term of its fabrication process, which also produce exhaust combustion with a high concentration of plumbum or lead.

The stated issue lead the researchers to construct new material for catalyst development in order to replace the Platinum Group Metal (PGM). According to Bagus et al., (2015) [15] in their studies on the new development of catalyst using Manganese Coated Copper $(\mathrm{CuMn})$, it is able to reduce the emission of carbon monoxide (CO). The decreasing of carbon monoxide pollutant gaseous is related to the changing of vehicles rpm. The analysed data taken from the experiment that has been run with the new development of catalytic converter shows that by increasing the cell numbers in the catalyst would reduce the carbon monoxide (CO) emission significantly. However, the usage of Manganese Coated Copper $(\mathrm{CuMn})$ as a catalyst for the converter only highly effect in reducing the carbon monoxide (CO) gas emission. The other gaseous such as nitrogen oxide $\left(\mathrm{NO}_{\mathrm{x}}\right)$ and unburned hydrocarbon (HC) is not being covered by this type of catalyst.

The usage of PGM is keep raising and demand also increasing which makes the concentration of these types of metal increased in the environment. According to Shahar and Majib (2007) [13], the concentration of Platinum (Pt) and Rhodium (Rh) has been taken upon road dust sample and the ratio range from the sample is in the range of $2.1: 1$ to $7: 1$, where the ratio these elements in the catalytic converter usage is $7: 1$. Kalam et al., (2009) [2] has also come with new ideas in the development of catalytic converter that used the material of titanium dioxide $\left(\mathrm{TiO}_{2}\right)$ and cobalt oxide $(\mathrm{CoO})$ as the catalyst material. The method is by using wire mesh substrate treatment immersed into a preparation of HCL solution. Titanium oxide (TiO) has its own properties as Bode et al., [16] state that the titanium is widely used in the automotive exhaust system as an oxidizing agent with lowcost fabrication. This new development of catalytic converter is tested with the original catalytic converter (OEM catco) that gives a positive feedback on the gaseous emission. The result concludes that the conversion efficiency of wire mesh catalyst and original catalytic converter (OEM catco) is $82 \%$ and $42 \%$. 
The usage of wire mesh in developing the substrate for the catalyst coating has its side effect. Even though the wire mesh will contribute to excellent mass and heat transfer with lower pressure drop, but the drawback of the wire mesh leads to the clogging effects because of high dust concentration, especially in solid fuel combustion. Another research was investigated by Kamariah et al., (2007) [17] using the woven stainless steel wire mesh to support the catalyst in reducing nitrogen oxide $\left(\mathrm{NO}_{\mathrm{x}}\right)$ gas emission. The mixture of Silica quartz, $\mathrm{SiO}_{2}$, and alumina, $\mathrm{Al}_{2} \mathrm{O}_{3}$ is used for the catalyst support. The area of woven stainless steel wire mesh (WSSWM) must be fully coated to avoid porosity on the catalyst surface as shown in Figure 1.

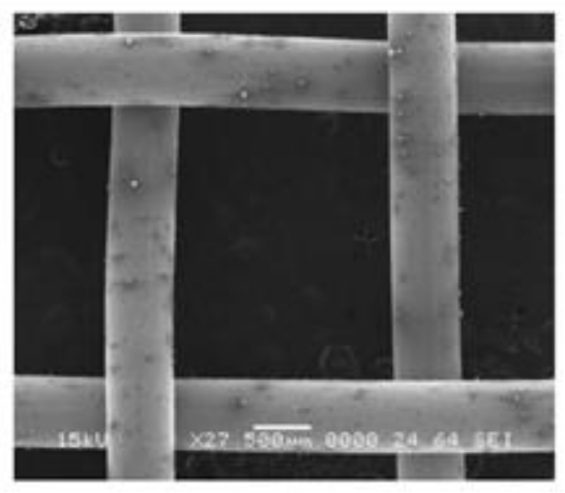

Fig. 1. Porosity on uncoated wire-mesh substrate.

In this study, a new type of catalytic converter based on nickel oxide (NiO)/ gammaalumina $\left(\gamma-\mathrm{Al}_{2} \mathrm{O}_{3}\right)$ materials has been selected to develop a catalyst to oxidise and reduce the pollutant gas emission. The advantage of the nickel type base catalyst is this material has high activity and firmness [22]. Nickel oxide catalyst (NiO) is a low-cost fabrication types, resistance to high temperature and domestically available in the market [18].

\subsection{Emission Gas Analysis and Simulation}

Simulation using software is quietly related with the mathematical models and codes parameter. According to Froment et al. [19] the use of the mathematical models in simulating models of catalytic reactors can give advantages where the formulation of such model is well documented. Kuipers et al., (1998) [20] support the above statement by stating that the development of the Computational Fluid Dynamics (CFD) codes is a useful introduction to the community. The evolution of the CFD Software might be used in various types of engineering field. Eriksson et al., (2004) [21] used the FLUENT Code to investigate the problems of particles that are overheating in a gas polymerization reactor. The investigation is done by the translation from the problems into a model of the moving gaseous particles.

\section{Methodology}

\subsection{Catalyst Preparation}

Nickel electroplating process is for depositing nickel onto FeCrAl. Electroplating is conducted on $\mathrm{FeCrAl}$ after new ultrasonic treatment. FeCrAl with the various sizes of $2 \mathrm{~cm}$ x $1 \mathrm{~cm}$, acted as a cathode with the various sizes acted as a cathode while a nickel plate 
substrate acted as an anode with the size of $4 \mathrm{~cm} \mathrm{x} 1 \mathrm{~cm}$ [22] (Sebayang et. al, 2012). Kalam et al., (2009) [2] prepared the catalyst by adding $10 \mathrm{gm}$ of $\mathrm{TiO}_{2}$ with sodium silicate in order to get $10 \% \mathrm{TiO}_{2}$ slurry before continuing with homogenization process that ends with drying process to get the catalyst slurry. The Same step is used by Syed et al., (2015) [23] by adding $10 \mathrm{gm} \mathrm{Al}_{2} \mathrm{O}_{3}$ with sodium silicate in order to get $\mathrm{Al}_{2} \mathrm{O}_{3}$ nanoparticles slurry. After the homogenization process takes place, the dip coating process is done before drying the catalyst in oven about 5 hours at $120^{\circ} \mathrm{C}$.

\subsection{Mathematical Model for Simulation}

A simulation for the gas emission flow distribution in the modified catalytic converter using ANSYS Software to be compared with the manual experiment. The simulation steps involved several previous steps such as developing of mathematical equation (thermodynamic) using for energy and mass balance, heat and mass transfer coefficient.

Thermodynamic reactions in one-dimensional system can be presented in a form of equations of mass balance of certain exhaust components and energy balance in gaseous phase and solid phase (on surface of catalyst walls). There is taken into account four exhaust components. Additionally, heat conduction can occur in the solid phase. These led to internal energy changes in the solid phase. The energy balance in the gas and solid phases can be expressed by Eq. 1 and 2, respectively [24]:

$$
\begin{gathered}
-\rho_{g} C_{\rho g} v_{m} \frac{d T_{g}}{d x}+\frac{4}{D_{H}} h\left(T_{s}-T_{g}\right)=0 \\
\frac{\partial}{\partial x}\left(k_{s} \delta_{w} \frac{\partial T_{s}}{\partial x}\right)-h\left(T_{s}-T_{g}\right)-\sum_{i} \Delta H_{R, i} R_{i, s}=\delta_{W} \rho_{S} C_{P S} \frac{\delta T_{S}}{\delta T}
\end{gathered}
$$

$\rho_{g}$ and $\rho_{S} \quad=$ Gas density and solid phase density

$C_{\rho g}$ and $C_{P S}=$ Constant pressure heat capacity in gas and solid phase, respectively in

$$
\mathrm{J} \mathrm{kg}^{-1} \mathrm{~K}^{-1}
$$

$v_{\mathrm{m}} \quad=$ Mean mass average velocity in $\mathrm{msec}^{-1}$

$\mathrm{h} \quad=$ Heat transfer coefficient in $\mathrm{W} \mathrm{m}^{-2} \mathrm{~K}^{-1}$

$T_{s}$ and $T_{g}=$ Temperature in gas and solid phases, respectively in $\mathrm{K}$

$\delta_{W} \quad=$ Reactor wall thickness in $\mathrm{m}$ and $\Delta H_{R, i}$ is enthalpy of reaction $\mathrm{I}$ in $\mathrm{J} \mathrm{mol}^{-1}$

\subsection{Simulation Result}

Refers to the result from the previous study, Mesut et al., (2013) [25] describe that the velocity for the exhaust emission gas using CFD analysis varies between $5.78 \mathrm{~m} / \mathrm{s}$ and 0.92 $\mathrm{m} / \mathrm{s}$. The increasing of velocity as expected is because of the reduction in exhaust cross section. According to Mohan et al., (2013) [26] the simulation tested on the velocity of 22.6 $\mathrm{m} / \mathrm{s}$ in the converter, it shows that the pressure change rapidly in the middle section of the converter while the pressure drop can be high which due to the inertial and viscous resistance of the porous media. Simon et al., (2010) [27] had simulated the pressure in catalyst and manifold of the vehicle exhaust in four selected design. The result concludes 
that catalyst yields a pressure drop about $10 \mathrm{kPa}$ where the four types of manifolds generate total pressure drop around 14.6, 12.2, 10.8 and $14.3 \mathrm{kPa}$.

\section{Conclusion}

The modification of the catalytic converter using FeCrAl as a substrate coated with $\gamma$ $\mathrm{A} 12 \mathrm{O} 3$ by using the ultrasonic and electroplating technique may improve the conversion of the pollutant. The data gained from the emission testing will be compared to the simulation of ANSYS FLUENT software in order to get the correspondent relation between the data. On the other hand, the simulation also will determine the effectiveness of the coated materials to the exhaust emission control and also influence to the lifetime of the materials.

This work was financially supported by Ministry of Education through FRGS Vote 1612 and ORICC, Universiti Tun Hussien Onn Malaysia (UTHM) for the management of the research grant and Centre for Graduate Studies - UTHM.

\section{References}

1. A.K.M. Mohiuddin, M. Nurhafez, International Journal of Mechanical and Materials Engineering, 2, 1 (2007)

2. M.A. Kalam, H.H. Masjuki, M. Redzuan, M.A. Fuad, M. Mohibah, K.H. Halim, M.I. Mahlia, A. Ishak, A. Yusoff, Sadhana, Acad. P. Eng. S., 34, 467 (2009)

3. S. Chuepeng, American Journal of Applied Sciences 9(8), 1225 (2012)

4. M. Mansha, A.H. Qureshi, I.A. Chaudry, E.M. Shahid, J. Qual. Technol., 9(1), 57 (2013)

5. K. Hakan, Ind. Lubr. Tribol., 53(6), 237 (2001)

6. S.R. Koteswara, R. Imam, K. Ramanathan, S. Pushpavanam, Ind. Eng. Chem. Res., 48(8), 3779 (2009)

7. M. Mansha, E.M. Shahid, A.H. Qureshi, Pak, J. Engg. \& Appl. Sci., 11, 114 (2012)

8. N. Gallopoulos. SAE Technical Paper, 920721 (1992)

9. D. Boam, T. Clark, K. Hobbs.SAE Technical Paper, 950930 (1995)

10. V. Ganessan, Internal Combustion Engine (McGraw Hill, New Delhi, 2004)

11. R.M. Heck, R.J. Farrauto, Catalytic Air Pollution Control (John Wiley \& Sons, New York, 2009)

12. S.E. Golunski, Platinum Metals Review., 51(3), 162 (2007)

13. H. Shahar, Amran Ab. Majib, Malaysian Journal of Analytical Sciences, 11(1), 145 (2007)

14. K. Ravindra, L. Bencs, R.V. Grieken, Sci. Total Environ., 318(1-3), 1 (2004)

15. R.M. Bagus Irawan, P. Purwanto, H. Hadiyanto, Procedia Environmental Sciences, 23, $86(2015)$

16. H. Bode, W. Maus, H. Swars, 17th International Engine Symposium, Vienna, (1996)

17. Kamariah Noor Ismail, Ku Halim Ku Hamid, Sharifah Aishah S. A. Kadir, Mohibah Musa, Robert Mikhail Savory, The Malaysian Journal of Analytical Sciences, 11(1), 246 (2007)

18. A. Firdianto, Ultrasonic Treatment With Nickel Electroplating Combined With Oxidation For Developing Gamma- $\mathrm{Al}_{2} \mathrm{O}_{3}$ Washcoat On Fe-Cr-Al Substrate (Diss UTHM, Batu Pahat, 2012).

19. G.B. Froment, K.B. Bischoff, Chemical Reactor Analysis and Design (Wiley, New York, 1990)

20. J.A.M. Kuipers, W.P.M. Van Swaaij, Advances in Chemical Engineering, 24, 227 (1998) 
21. J.G. Eriksson, T.F. Mckenna, Ind. Eng. Chem. Res., 43, 7251 (2004)

22. Darwin Sebayang, Yanuandri Putrasari, Sulaiman Hasan, Mohd Ashraf Othman, Pudji Untoro, Preparation of NiO Catalyst on FeCrAl Substrate Using Various Techniques at Higher Oxidation Process, Electroplating (INTECH, Crotia, 2012)

23. C. Syed Aalam, C.G. Saravanan, C. Mohamed Samath, International Journal For Research In Emerging Science And Technology, 2(7), 17 (2015)

24. R.E. Hayes, S.T. Kolaczkowski, Introduction to Catalytic Combustion (CRC Press, Amsterdam, 1998).

25. Mesut Durat, Zekeriya Parlak, Murat Kapsiz, Adnan Parlak, Ferit Fiçici, Journal of Thermal Science and Technology, 33(2), 89 (2013)

26. K. Mohan Laxmi, V. Ranjith Kumar, Y.V. Hanumantha Rao, International Journal of Engineering Research and Applications, 3(3), 518 (2013)

27. M.S. Simon Martinez, D. Ruben, A. Leal-Garza Fausto, Sanchez. Cruz, Esteban Baez Villarreal, Journal of KONES., 17(4), 303 (2010) 